\title{
PHYTOCHEMICAL SCREENING AND GAS CHROMATOGRAPHY-MASS SPECTROSCOPY ANALYSIS OF BIOACTIVE COMPOUNDS AND BIOSYNTHESIS OF SILVER NANOPARTICLES USING SPROUT EXTRACTS OF VIGNA RADIATA L. AND THEIR ANTIOXIDANT AND ANTIBACTERIAL ACTIVITY
}

\author{
SIVAKUMAR T* \\ Department of Botany, Annamalai University, Chidambaram, Tamil Nadu, India. Email: drtsivanano@gmail.com \\ Received: 21 August 2018, Revised and Accepted: 11 October 2018
}

ABSTRACT

Objectives: The present study was aimed to investigate the facile synthesis of silver nanoparticles (AgNPs) using the green gram sprout extract (GGSE) of Vigna radiata L. and also in vitro studies of antioxidant and antimicrobial activities.

Methods: Gas chromatography-mass spectroscopy techniques have been used for the qualitative and quantitative evaluation of the phytochemicals present in the green gram seedlings. The antioxidant activity of AgNPs and GGSE was analyzed using the 1,1-diphenyl-2-picrylhydrazyl (DPPH) assay. In vitro antibacterial activity was performed using the agar well diffusion method.

Results: The presence of various secondary metabolites such as flavonoids, steroids, terpenoids, alkaloids, amino acids, polyphenol, glycoside, and protein was found in samples. The major chemical compounds of $V$. radiata were n-hexadecanoic acid, stigmasterol, caffeine, hexadecanoic acid, cholest-5-en-3-ol (3.beta.)-, and cyclopentane. The percentage of DPPH activity was enhanced on increasing the concentration of AgNPs. In vitro antibacterial effect of the diverse concentrations of AgNPs was investigated against each Gram-negative (Klebsiella aerogenes, and Escherichia coli) and Gram-positive (Bacillus substilis and Staphylococcus aureus) bacterial strains.

Conclusion: The result suggests that biosynthesized AgNPs have good antibacterial and antioxidant activity and might be a potential for the bioactive components.

Keywords: Vigna radiata, Green synthesis, Silver nanoparticles, Gas chromatography-mass spectroscopy, 1,1-Diphenyl-2-picrylhydrazyl, Antibacterial activity.

(C) 2019 The Authors. Published by Innovare Academic Sciences Pvt Ltd. This is an open access article under the CC BY license (http://creativecommons. org/licenses/by/4. 0/) DOI: http://dx.doi.org/10.22159/ajpcr.2019.v12i2.29253

\section{INTRODUCTION}

Nanoscience research shows exponential growth, especially with potential applications in biomedical science and technology. Currently, metallic nanoparticles such as silver, gold, and platinum are focused much for specific optical, mechanical, and chemical properties than bulk metal [1]. Among these metal nanoparticles, silver plays a key role in fabric and pharmaceutical industries [2]. A wide spectrum of methods to synthesize AgNP is well documented. For example, distinct electrochemical method, sono-chemical, radiation, microwave assisted method, opposite micelles technique, segment transfer procedure, photochemical synthesis, organic strategies [3-10]. These methods involve the use of toxic substance and pose serious environmental and health problem. In recent years, metal nanoparticles protected by bioorganic ligand are involved in a great deal due to their widespread applications [11]

In current years, the facile synthesis of AgNPs with the aid of biologically active compounds has been extensively explored due to its easy availability and eco-friendliness [12]. Biosynthesized silver nanoparticle (AgNP) using Eucalyptus chapmaniana [13], Terminalia bellirica [14], Acalypha indica [15], and Cynodon dactylon [16] plant extracts has been acknowledged, and the applications of AgNPs in the detection of cancer, combating of microbes, bio-labeling, and drug transport are reported [17]. Biosynthesized nanoparticles are used in water filters, textile, and food industries due to their antimicrobial activities [18].

In the past few years, gas chromatography-mass spectrometry (GC-MS) has become a versatile tool for secondary metabolite profiling in both plant and non-plant species [19,20]. GC-MS analysis provides accurate results of analyte even at low concentrations. GC-MS analyses are extensively utilized in forensic science, elemental analysis, and pollution research [21]. In recent times, the bioactive additives tagged with nonpolar, volatile substances, alkaloids, phenols, long chain and branchedchain hydrocarbons, alcohols, acids, esters, and different biologically energetic additives are being separated using GC-MS [22,23]. AgNPs prepared using green gram sprout extract (GGSE) (Leguminosae family) and characterized by UV-spectrum, X-ray diffraction, Fourier-transform infrared, standard error of the mean, and tested on antimicrobial activity using some microbes were published by our research group [24]. In this work, the author reported the phytochemical analysis, GC-MS, and antioxidant activity of AgNPs.

\section{METHODS}

Preparation of GGSE

Quality seeds of Vigna radiata (green gram) obtained from the agro seed shop were washed and covered in a smooth moist cloth. The seeds began to sprout after germination time of 1-2 days. The sprouts were gathered and dried in the shade at room temperature $\left(30^{\circ} \mathrm{C}\right)$. Electric blender was used to powder the dried sprouts. Cloth sieve is used to collect the fine powder of GGSE and is collected in airtight container for further studies.

\section{Chemicals and reagents}

Ascorbic acid, methanol, silver nitrate $\left(\mathrm{AgNO}_{3}\right)$, and 2,2-diphenyl1-picrylhydrazyl (DPPH) have been bought from Sigma-Aldrich. All reagents were of analytical grade. 
Biosynthesis of AgNPs

About $5 \mathrm{~g}$ of dry sprout powder was boiled with $30 \mathrm{ml}$ of deionized water for $30 \mathrm{~min}$, then cooled and filtered using Whatman No 1 paper. This GGSE was stored in refrigerator for further use. The GGSE is used as reducing agent to reduce $\mathrm{AgNO}_{3}$ to $\mathrm{Ag} .0 .1 \mathrm{mM} \mathrm{AgNO}_{3}$ was prepared by dissolving $60 \mathrm{mg}$ of $\mathrm{AgNO}_{3}$ in $360 \mathrm{ml}$ deionized water. To this solution, $40 \mathrm{ml}$ of GGSE was added and stirred for 30 min using a magnetic stirrer. A color change from pale brown to reddish brown was observed within $2 \mathrm{~h}$. The color change indicated the formation of AgNPs. The reddish-brown solution obtained was centrifuged (1200 rpm) for $15 \mathrm{~min}$, washed the precipitate, and dried in Petri dish at $35^{\circ} \mathrm{C}$. This dried powder was used for phytochemical screening, GCMS analysis, and antioxidant and antibacterial activities.

\section{Qualitative phytochemical screening}

Preliminary phytochemical screening of GGSE was made for the qualitative detection of various phytocompounds which include flavonoids, steroids, terpenoids, alkaloids, amino acids, polyphenol, glycoside, and protein. Preliminary phytochemicals were analyzed by conventional methods as described by Al-Owaisi et al. [25] and Sheel et al. [26].

\section{Preparation of plant extract for GC-MS analysis}

The freshly grown GGS was washed very well in tap water, shade dried, and powdered in a blender $50 \mathrm{~g}$ of sprout powder was mixed with methanol and stored inside the conical flask for 1 week. After 7 days, extract had been filtered with Whatman No. 1 filter paper. The filtrated methanol extracts are dried and used for GC-MS studies. GC-MS analysis was performed using Shimadzu QP 2010 plus mass analyzer. (injection mode: Normal, column oven temperature: $100^{\circ} \mathrm{C}$, and injection temperature: $250^{\circ} \mathrm{C}$ ). Each component was calculated by comparing the average peak area to the total area for relative peak area. The National Institute of Standards and Technology (NIST) database is used to identify $>62,000$ patterns of individual components. The unknown sample spectrum was compared with the spectrum of known component saved in the NIST library. The element name, shape, and molecular weight of the test sample had been ascertained.

\section{DPPH free radical scavenging activity}

The free radical scavenging (DPPH) activity for synthesized nanoparticles and GGSE was analyzed spectrophotometrically (517 $\mathrm{nm}$ ) with the approach mentioned by Govindappa et al. [27]. In vitro antioxidant activity was measured in terms of standard ascorbic acid antioxidant equivalents. The percentage of antioxidant activity was calculated using the equation $=[(a-b) / a] \times 100$, where control [blank $(a)]$ was prepared and $b$ is the observance of the samples.

\section{Bacterial source and antibacterial activity}

Bacterial strains of Klebsiella aerogenes (MTCC 98), Escherichia coli (MTCC 443), Bacillus subtilis (MTCC 2295), and Staphylococcus aureus (MTCC 3160) were used and maintained in nutrient agar (Hi-Media, Mumbai) slants at $4^{\circ} \mathrm{C}$. AgNPs and its antibacterial activity were analyzed using an agar well diffusion approach as reported by Gudikandula and Maringanti [28]. Gram-negative bacteria, namely E. coli (MTCC 443) and K. aerogenes (MTCC 98), and Gram-positive bacteria, namely B. subtilis (MTCC 2295) and S. aureus (MTCC 3160), were used. Mueller-Hinton Agar (Hi-Media, Mumbai) plates were prepared, sterilized, solidified, and swabbed uniformly. 6-mm length four wells roughly were made on the prepared plates using gel puncture. Different concentrations of AgNPs $(10,20,30$, and $40 \mu \mathrm{L})$ were loaded into the wells of all plates. The plates were analyzed for zone of inhibition after incubition time $\left(24 \mathrm{~h}\right.$ at $\left.37^{\circ} \mathrm{C}\right)$.

\section{Statistical analysis}

Experiments were performed in triplicates, and the results are expressed as mean \pm standard deviation. The statistical analysis was made with origin software (OriginPro evaluation, 2018).

\section{RESULTS AND DISCUSSION}

\section{Biosynthesis of AgNPs and the usage of GGSE}

The GGSE was blended with the aqueous extract of synthesized $\mathrm{AgNO}_{3}$ at room temperature. The various stages of AgNP formation are shown in Fig. 1. After $30 \mathrm{~min}$, the initial color change was observed and a brownish red coloration was obtained after $2 \mathrm{~h}$ as shown in Fig. 2. The final color change indicates the completion of AgNP synthesis process. The change in color from watery to brownish red color indicates the formation of AgNPs and this variation is attributed due to surface plasmon resonance of AgNPs within the reaction samples $[29,30]$.

\section{Qualitative phytochemical screening}

The qualitative phytochemical screening of methanolic GGSE is shown in Table 1. Phytochemical screening showed the presence of

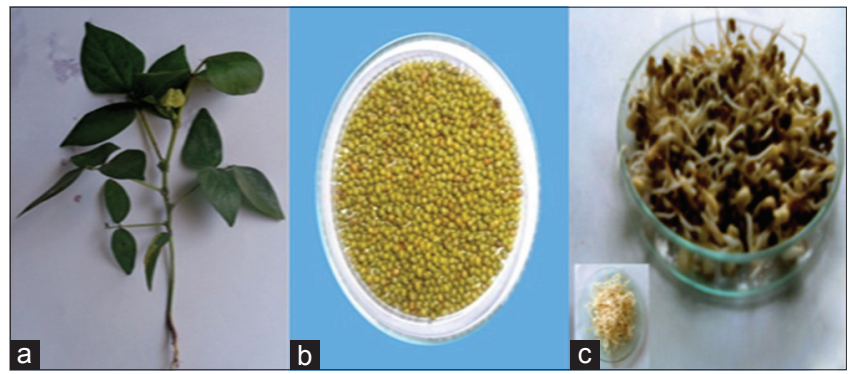

Fig. 1: Biosynthesis of silver nanoparticles using Vigna radiate. (a) Whole plant, (b) fine seeds, (c) sprouts

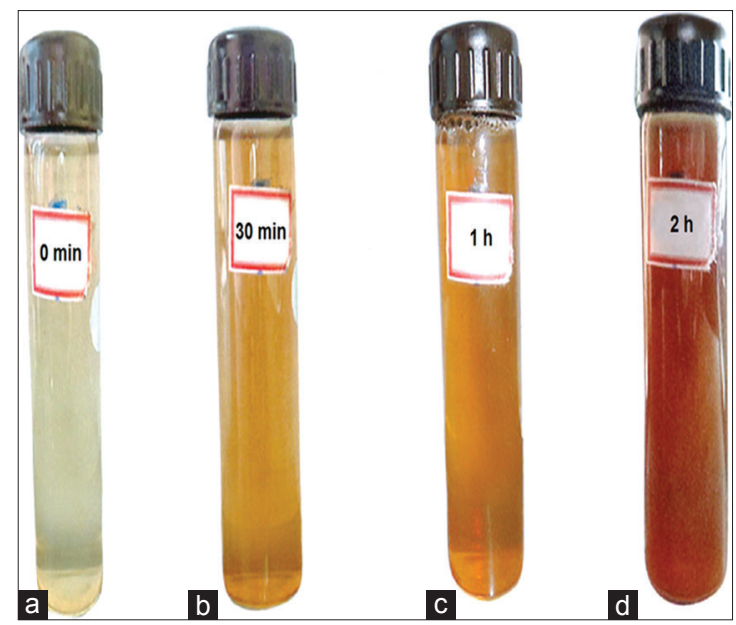

Fig. 2: Biosynthesis of silver nanoparticles using green gram sprout extract of Vigna radiata. (a) $\mathrm{AgNO}_{3}+$ sprout extract $0 \mathrm{~min}$, (b) $30 \mathrm{~min}$, (c) $1 \mathrm{~h}$, (d) $2 \mathrm{~h}$

Table 1: Phytochemicals screening results of green gram sprout extracts

\begin{tabular}{lll}
\hline S. No. & Phytochemical & Results (qualitative) \\
\hline 1 & Tannin & --- \\
2 & Saponin & --- \\
3 & Flavonoids & ++ \\
4 & Steroids & +++ \\
5 & Terpenoids & ++ \\
6 & Alkaloids & +++ \\
7 & Amino acids & +++ \\
8 & Polyphenol & +++ \\
9 & Glycoside & +++ \\
10 & Protein & ++ \\
\hline$-:$ Absence, +: Presence,,$+++++:$ Indicates intensity of color
\end{tabular}


flavonoids, steroids, terpenoids, alkaloids, amino acids, polyphenol, glycoside, and protein. It is reported that the leaves of $D$. montana have steroids, flavonoids, and phenols [31]. Biologically active compounds might play a large role in forming, capping, and stabilization of AgNPs [32].

\section{GC-MS analysis}

The outcomes of the GC-MS evaluation confirmed that 24 compounds (Fig. 3) have been present in GGSE. These compounds have been diagnosed using GC-MS. The mass spectra of those compounds matched with the ones found within the NIST/NBS spectral database and the information are given in Table 2. The important compounds of GGSE (retention time 30.027) were found to be stigmast-5-en3-ol, (3-beta), stigmasterol, pregnane, silane derivative trimethylsilyl ester of tetracosanoic acid, 9-octadecenoic acid (z) 2 , n-hexadecanoic acid, mome inositol, and ethyl alpha-d-glucopyranoside stated to own antioxidant, antibacterial, anticancer, hepatoprotective, anti-inflammatory, and antimicrobial and inhibition of parasitic increase [33].

\section{Antioxidant activity}

The free radical scavenging capabilities of biosynthesized AgNPs and GGSE were made using the DPPH assay. In DPPH assay, the antioxidant activities of AgNPs and the GGSE were found increased as the concentration of samples used for assay changed from 20 to $100 \mu \mathrm{g} / \mathrm{mL}$ (Fig. 4). In general, GGSE-mediated biosynthesized AgNPs have the good antioxidant capacity as that of the standard (ascorbic acid). This is due to the presence of phytocompounds that might have radical scavenging activity, particularly polyphenols which are a potential hydrogen atom donor [34]. The presence of antioxidant outcomes indicated that free radical scavenging activity of AgNPs has increased concentrationdependent way.

\section{Antibacterial activity}

Antibacterial activity of synthesized AgNPs showed positive results toward the Gram-positive and Gram-negative microorganism. The antibacterial activity was found to be maximum for $K$. aerogenes, followed by E. coli, B. subtilis, and S. aureus (Fig. 5). From the results, it is obvious that the inhibition activity of AgNPs toward Gram-negative bacterial traces was higher than toward the Gram-positive bacteria. This

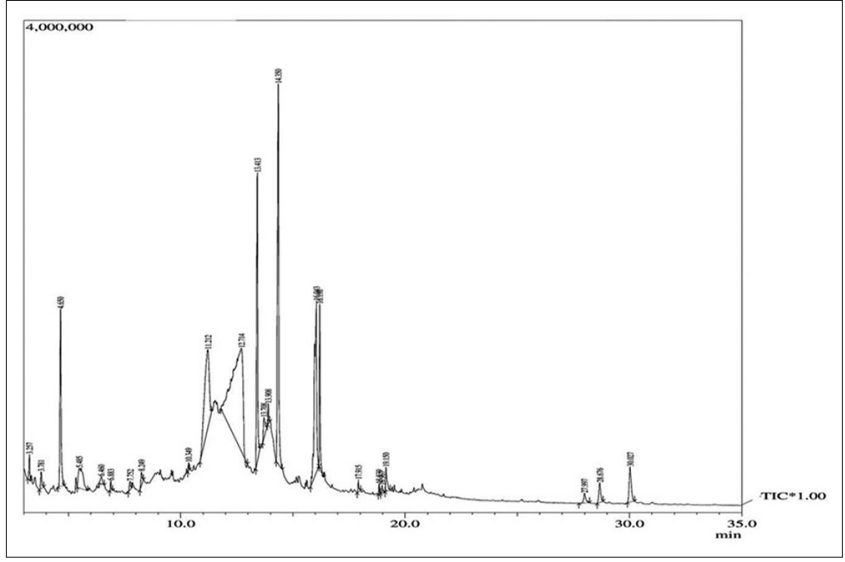

Fig. 3: Chromatogram of green gram sprout sample

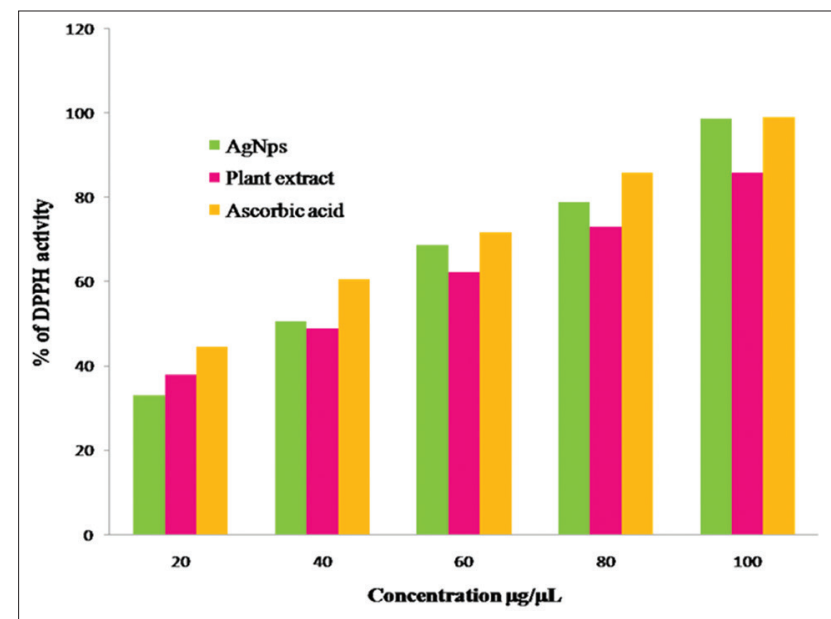

Fig. 4: 1,1-Diphenyl-2-picrylhydrazyl antioxidant activity of silver nanoparticles and green gram sprout extract of Vigna radiata

Table 2: Peak report derived from the chromatogram of the green gram sprout

\begin{tabular}{|c|c|c|c|c|}
\hline Peak $^{\#}$ & R. Time & Area & Area \% & Name \\
\hline 1 & 3.257 & 588627 & 0.69 & 1-Butanamine, 2-methyl-N-(2-methylbutylidene) \\
\hline 2 & 3.781 & 564406 & 0.67 & Cyclopentane, 1-acetyl-1,2-epoxy- \\
\hline 3 & 4.650 & 5036211 & 5.94 & 4H-Pyran-4-one, 2,3-dihydro-3,5-dihydroxy-6-methyl \\
\hline 4 & 5.485 & 2425030 & 2.86 & 1-Deoxy-d-arabitol \\
\hline 5 & 6.460 & 388872 & 0.46 & 2-Ethylhexyl pentenoate \\
\hline 6 & 6.883 & 231882 & 0.27 & 1-Heptanol, 2-propyl \\
\hline 7 & 7.752 & 295200 & 0.35 & 3-(4-Aminobutyl) piperidine \\
\hline 9 & 10.349 & 144343 & 0.17 & 1H-Pyrrole, 2-(2,4,6-cycloheptatrienyl) \\
\hline 10 & 11.212 & 9582380 & 11.31 & Ethyl alpha-d-glucopyranoside \\
\hline 11 & 12.714 & 26132753 & 30.83 & Mome inositol \\
\hline 12 & 13.413 & 7436423 & 8.77 & Caffeine \\
\hline 13 & 13.708 & 895705 & 1.06 & 1H-Purine-2,6-dione, 3,7-dihydro-3,7-dimethyl \\
\hline 14 & 13.908 & 335443 & 0.40 & Hexadecanoic acid, methyl ester \\
\hline 15 & 14.350 & 12098730 & 14.27 & n-Hexadecanoic acid \\
\hline 16 & 16.043 & 9915501 & 11.70 & Unknown \\
\hline 18 & 17.915 & 308432 & 0.36 & 9-Octadecenoic acid (Z) \\
\hline 19 & 18.839 & 197121 & 0.23 & Trimethylsilyl ester of tetracosanoic acid \\
\hline 20 & 18.967 & 200087 & 0.24 & Pregnane, silane derivative \\
\hline 21 & 19.150 & 896508 & 1.06 & Hexadecanoic acid, 2-hydroxy-1-(hydroxymethyl) ethyl ester \\
\hline 22 & 27.997 & 488264 & 0.58 & Cholest-5-en-3-ol (3-beta)-, carbonochloridate \\
\hline 23 & 28.676 & 979558 & 1.16 & Stigmasterol \\
\hline 24 & 30.027 & 1886587 & 2.23 & Stigmast-5-en-3-ol (3-beta) \\
\hline Total & & 84761717 & 100.00 & \\
\hline
\end{tabular}




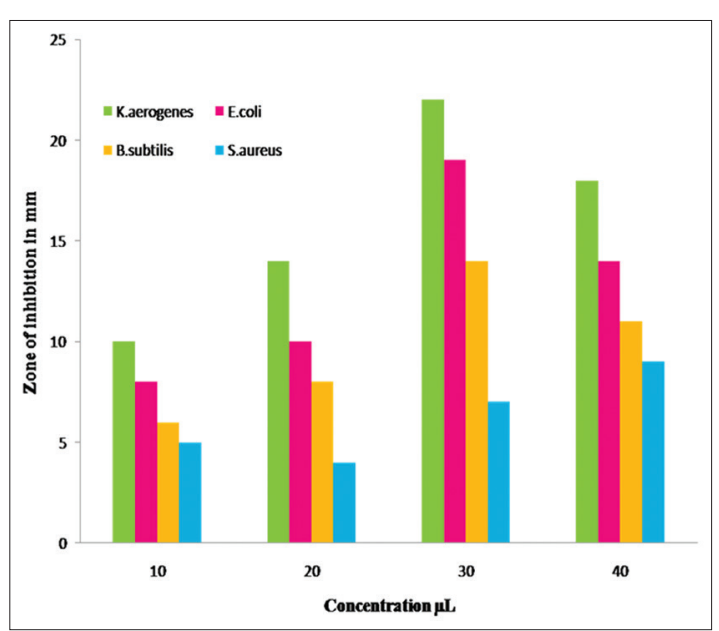

Fig. 5: Zone of inhibitions of silver nanoparticles against Grampositive and Gram-negative bacteria through continuous culture method

could be attributed to the fact that the Gram-negative microorganisms have a thin peptidoglycan layer, but the Gram-positive microorganisms have a thick peptidoglycan layer [35].

\section{CONCLUSION}

The GGSE-assisted biosynthesis of AgNPs was found to be a convenient green route and cost-effective method. Phytochemicals present in the sprout extract act as a strong reducing and capping agent for the formation of AgNPs. The GGSE-assisted biosynthesis of AgNPs has shown potential antibacterial and antioxidant activity and proved to be an effective antibacterial material.

\section{ACKNOWLEDGMENT}

The author would like to thank all organizations which provide facilities for this work and all the professors who cooperated in technical assistance.

\section{AUTHOR'S CONTRIBUTIONS}

The idea is mine, I have designed the work, experiments were carried out by me, and the paper is also written by me.

\section{CONFLICTS OF INTEREST}

There are no conflicts of interest in this article.

\section{REFERENCES}

1. Dauthal P, Mukhopadhyay M. In-vitro free radical scavenging activity of biosynthesized gold and silver nanoparticles using Prunus armeniaca (apricot) fruit extract. J Nanopart Res 2013;15:1-11

2. Mie R, Samsudin MW, Din LB, Ahmad A, Ibrahim N, Adnan SN, et al. Synthesis of silver nanoparticles with antibacterial activity using the lichen Parmotrema praesorediosum. Int J Nanomedicine 2014;9:121-7.

3. Starowicz M, Stypuła B, Banaś J. Electrochemical synthesis of silver nanoparticles. Electrochem Commun 2006;8:227-30.

4. Talebi J, Halladj R, Askari S. Sonochemical synthesis of silver nanoparticles in Y-zeolite substrate. J Mater Sci 2010;45:3318-24.

5. Temgire MK, Joshi SS. Optical and structural studies of silver nanoparticles. Radiat Phys Chem 2004;71:1039-44.

6. Siamaki AR, Abd El Rahman SK, Abdelsayed V, El-Shall MS, Gupton BF. Microwave-assisted synthesis of palladium nanoparticles supported on graphene: A highly active and recyclable catalyst for carbon-carbon cross-coupling reactions. J Catal 2011;279:1-11.

7. Bae DS, Kim J, Bang JH, Kim SW, Han, KS, Lee JK, et al. Synthesis and characterization of silver nanoparticles by a reverse micelle process. Met Mater Int 2005;11:291-4.

8. Ankamwar B, Damle C, Ahmad A, Sastry M. Biosynthesis of gold and silver nanoparticles using Emblica officinalis fruit extract, their phase transfer and transmetallation in an organic solution. J Nanosci Nanotechnol 2005;5:1665-71.

9. Jin R, Cao Y, Mirkin CA, Kelly KL, Schatz GC, Zheng JG. Photo induced conversion of silver nanospheres to nanoprisms. Science 2001;294:1901-3.

10. Kathiravan V, Ravi S, Ashokkumar S. Synthesis of silver nanoparticles from melia dubia leaf extract and their in vitro anticancer activity. Spectrochim Acta A Mol Biomol Spectrosc 2014;130:116-21.

11. Ponarulselvam S, Panneerselvam C, Murugan K, Aarthi N, Kalimuthu K, Thangamani S, et al. Synthesis of silver nanoparticles using leaves of Catharanthus roseus linn. G. Don and their antiplasmodial activities. Asian Pac J Trop Biomed 2012;2:574-80.

12. Das R, Gang S, Nath SS. Preparation and antibacterial activity of silver nanoparticles. J Biomater Nanobiotechnol 2011;2:472-5.

13. Ajitha B, Reddy YA, Reddy PS. Biosynthesis of silver nanoparticles using Momordica charantia leaf broth: Evaluation of their innate antimicrobial and catalytic activities. J Photochem Photobiol B 2015;146:1-9.

14. Sulaiman GM, Mohammed WH, Marzoog TR, Al-Amiery AA, Kadhum AA, Mohamad AB, et al. Green synthesis, antimicrobial and cytotoxic effects of silver nanoparticles using Eucalyptus chapmaniana leaves extract. Asian Pac J Trop Biomed 2013;3:58-63.

15. Krishnaraj C, Jagan EG, Rajasekar S, Selvakumar P, Kalaichelvan PT, Mohan N, et al. Synthesis of silver nanoparticles using Acalypha indica leaf extracts and its antibacterial activity against water borne pathogens. Colloids Surf B Biointerfaces 2010;76:50-6.

16. Supraja S, Ali SM, Chakravarthy N, Priya AJ, Sagadevan E, Kasinathan MK, et al. Green synthesis of silver nanoparticles from Cynodon dactylon leaf extract. Int J Chem Tech 2013;5:271-7.

17. Manivasagan P, Venkatesan J, Senthilkumar K, Sivakumar S, Kim K. Biosynthesis, antimicrobial and cytotoxic effect of silver nanoparticles using a novel Nocardiopsis sp. MBRC-1. Res Biomed 2013;8:1-9.

18. Robertson DG. Metabonomics in toxicology: A review. Toxicol Sci 2005;85:809-22.

19. Fernie AR, Trethewey RN, Krotzky AJ, Willmitzer L. Metabolite profiling: From diagnostics to systems biology. Nat Rev Mol Cell Biol 2004:5:763-9.

20. Kell DB, Brown M, Davey HM, Dunn WB, Spasic I, Oliver SG, et al. Metabolic footprinting and systems biology: The medium is the message. Nat Rev Microbiol 2005;3:557-65.

21. Konovalova O, Gergel E, Herhel V. GC-MS analysis of bioactive components of Shepherdia argentea (Pursh.). Nutt Ukranian Flora Pharm Innov J 2013;2:7-12.

22. Kalaivani CS, Sathish SS, Janakiraman N, Johnson M. GC-MS studies on Andrographis paniculata (Burm. f.) Wall. Ex nees-a medicinally important plant. Int J Med Arom Plants 2012;2:69-74

23. Venkataraman B, Samuel LA, Saradhi MP, Rao BN, Vamsi N, Krishna A. Antibacterial, antioxidant activity and GC-MS analysis of Eupaturium odoratum. Asian J Pharm Clin Res 2012;5:99-106.

24. Senthilkumar SR, Sivakumar T. Studies on the greengram (Vigna radiata $\mathrm{L}$.) sprout assisted synthesis of silver nanoparticles and their antimicrobial activities. Int J Nanomat Biostruct 2014;4:52-7.

25. Al-Owaisi M, Al-Hadiwi N, Khan SA. GC-MS analysis, determination of total phenolics, flavonoid content and free radical scavenging activities of various crude extracts of Moringa peregrina (Forssk.) fiori leaves. Asian Pac J Trop Med 2014;4:964-70.

26. Sheel R, Nisha K, Kumar J. Preliminary phytochemical screening of methanolic extract of Clerodendron infortunatum. IOSR J Appl Chem 2014;7:10-3

27. Govindappa M, Channabasava R, Kumar KS, Pushpalatha KC. Antioxidant activity and phytochemical screening of crude endophytes extracts of Tabebuia argentea Bur. \& K. Sch. Am J Plant Sci 2013;4:1641-52

28. Gudikandula K, Maringanti SC. Synthesis of silver nanoparticles by chemical and biological methods and their antimicrobial properties. J Exp Nanosci 2016;11:714-21.

29. Vanaja M, Gnanajobitha G, Paulkumar K. Phytosynthesis of silver nanoparticles by Cissus quadrangularis: Influence of physicochemical factors. J Nanostruct Chem 2013;3:17-25.

30. Kumar B, Smita K, Cumbal L, Debut A. Green synthesis of silver nanoparticles using andean blackberry fruit extract. Saudi J Biol Sci 2017;24:45-50.

31. Ebbo AA, Mammam M, Suleiman MM, Ahmed A, Bello A. Preliminary phytochemical screening of Diospyros mespiliformis. Anat Physiol 2014;4:2161.

32. Oluwaniyi OO, Adegoke HI, Adesuji ET, Alabi AB, Bodede SO, Labulo $\mathrm{AH}$, et al. Biosynthesis of silver nanoparticles using aqueous 
leaf extracts of Thevetia peruviana Juss and its antimicrobial activities. Appl Nanosci 2016;6:903-12.

33. Anand T, Gokulakrishnan K. Phytochemical analysis of Hybanthus enneaspermus using UV, FTIR and GC-MS. IOSR J Pharm 2012;2:520-4.

34. Sagbo IJ, Afolayan AJ, Bradley G. Antioxidant antibacterial and phytochemical properties of two medicinal plants against the wound infecting bacteria. Asian Pac J Trop Biomed 2017;7:817-25.

35. Kokila T, Ramesh PS, Geetha D. Biosynthesis of silver nanoparticles from cavendish banana peel extract and its antibacterial and free radical scavenging assay: A novel biological approach. Appl Nanosci 2015;5:911-20 